\title{
LIBERTAD ESPIRITUAL Y LIBERTADES CIVILES EN LA NARRATIVA Y LA DRAMATURGIA DE GRISELDA GAMBARO
}

\author{
Susana Tarantuviez \\ Universidad Nacional de Cuyo - \\ Consejo Nacional de Investigaciones Científicas y Técnicas (CONICET) \\ Argentina \\ sutarantuviez@hotmail.com
}

doi.org/ 10.15452/SR.2020.20.0012

\begin{abstract}
Resumen. En este trabajo se da a conocer parte de la novelística y la dramaturgia de la escritora argentina contemporánea Griselda Gambaro (Buenos Aires, 1928). En particular, se analiza la cuestión de la libertad de elección ante dilemas morales, éticos y políticos que presentan algunos de sus personajes y su actitud frente a la carencia de libertades civiles del ambiente en el que se desarrolla cada historia. Se estudia específicamente a las protagonistas de sus novelas Ganarse la muerte y Dios no nos quiere contentos y de sus obras de teatro La malasangre, Real envido, Del sol naciente y Antígona furiosa. Se constata que, tanto en los textos narrativos como dramáticos analizados, la autora plantea que incluso ante las peores adversidades, del ámbito privado o público, la libertad esencial del ser humano se preserva y le permite elegir su propia y única actitud ante las situaciones de desamparo, opresión o violencia sufridas. Se trata de una libertad espiritual que se sostiene incluso en las más terribles circunstancias de tensión psíquica y física. Se concluye que estos personajes representan una cosmovisión en la cual al ser humano puede arrebatársele todo, excepto la más esencial de las libertades humanas: el libre albedrío para elegir la actitud personal ante un conjunto de circunstancias y decidir el propio camino.
\end{abstract}

Palabras clave. Griselda Gambaro. Literatura argentina. Narrativa. Dramaturgia. Libertad. Libertades civiles.

Abstract. Spiritual Freedom and Civil Rights in Griselda Gambaro's Narrative and Dramaturgy. This paper approaches the novels and plays created by the contemporary Argentine writer Griselda Gambaro (born in Buenos Aires, in 1928). In particular, it reviews how 
some of her characters deal with the issue of freedom of choice in the face of moral, ethical and political dilemmas, as well as their attitude towards the lack of civil rights in the context in which each story takes place. The protagonists of her novels Ganarse la muerte and Dios no nos quiere contentos, and of her plays La malasangre, Real envido, Del sol naciente, and Antígona furiosa are put into close consideration. In these narrative and dramatic texts, the author argues that even in the face of the worst adversities, in the private or public sphere, the essential freedom of the human being is preserved and allows him/her to choose his/her own unique attitude in situations of helplessness, oppression or violence. It is a spiritual freedom that is sustained even in the most terrible circumstances of psychic and physical suffering. The conclusion is that these characters represent a worldview in which the human being can be deprived of everything, except the most essential of human liberties, that is the free will to choose a personal attitude to a set of circumstances and decide his/her own path.

Keywords. Griselda Gambaro. Argentinian Literature. Narrative. Plays. Freedom. Civil Rights. 


\section{Introducción}

La escritora argentina Griselda Gambaro afirma que sus diversas prácticas discursivas, en tanto dramaturga y en tanto narradora, le permiten acceder a dos modos diferentes del hacer literario:

Gambaro defiende la narrativa y el teatro en tanto «alternativas de trabajo», opciones legítimas de acercarse al público. Si valora la calidad colectiva del fenómeno teatral en «un público presente que termine el espectáculo», también anota en la novela una calidad particularmente reflexiva e introspectiva (Morell, 1991: 482).

El teatro le permite entablar una comunicación de tipo colectivo, mientras que su narrativa le ofrece a los lectores una mayor reflexión especulativa. Este espacio reflexivo de su novelística le ha permitido abordar con profundidad el tema de la libertad, tanto política como espiritual.

Cabe señalar que, a principios de este siglo, Griselda Gambaro era reconocida casi únicamente por su producción dramática, mientras que su obra narrativa todavía no había sido suficientemente descubierta: hasta principios del siglo XXI, no existía un corpus crítico significativo acerca de su producción como narradora. En efecto, al evaluar su inclusión en el canon narrativo argentino, nos encontrábamos con una gran falta de estudios teórico-críticos sobre sus novelas y cuentos, a pesar de haber entrado a la narrativa argentina ya en la década de 1960 con las «nouvelles» Madrigal en ciudad (1963) y El desatino (1965) y la novela Una felicidad con menos pena (1967). Fue su obra dramática, en cambio, iniciada con el estreno de El desatino en 1965', la que le otorgó el reconocimiento de la crítica especializada, y así su dramaturgia, no su narrativa $^{2}$, se convirtió en el centro de los estudios críticos gambarianos durante todo el siglo XX.

Los universos ficcionales creados en las novelas y obras teatrales que comento a continuación configuran un panorama desolador de violencia y represión, en el cual, sin embargo, hay personajes que sostienen una axiología positiva y conservan su libertad espiritual para llevar a cabo acciones solidarias, de amorosa generosidad, incluso en medio de la falta total de libertades y derechos civiles, lo cual indica una elección ideológica por parte de Gambaro. Esta toma de posición se completa con otros textos y declaraciones de la autora. Baste decir aquí, a modo de ejemplo, que en su «diario literario» Escritos inocentes, Gambaro narra, bajo el título «Una historia de amor» (Gambaro, 1999: 48-51), la historia de un joven soldado alemán en un campo de concentración nazi quien, enamorado de una prisionera checa, decide viajar a Checoslovaquia para llevar noticias de las presas a sus familiares. Su idea «loca, generosa y solidaria» es una «luz en la densa oscuridad». No es casual que sea esta historia, que resume paradigmáticamente la postura de Gambaro ante el vínculo con el prójimo, la que la autora elige narrar, cuando se le pide que cuente algunas cosas de Escritos inocentes, en una entrevista radial llevada a cabo el

1 Si bien Las paredes es un texto dramático anterior, de 1963, no será estrenado hasta 1966.

2 Al día de hoy, Griselda Gambaro cuenta con una valiosa obra narrativa publicada, en la que se destacan las novelas Ganarse la muerte (1976), Dios no nos quiere contentos (1979), Después del día de fiesta (1994), El mar que nos trajo (2002) y Promesas y desvaríos (2004). Griselda Gambaro también ha escrito una novela erótica, Lo impenetrable (1984), con el fin de participar en España en el concurso «La sonrisa vertical» (de la editorial Tusquets), un texto atípico en su producción. 
año siguiente a la publicación de su diario ${ }^{3}$. Asimismo, al hablarnos acerca de la pluralidad de sentidos de todo libro y, específicamente de su novela Después del día de fiesta, la autora indicó una posible lectura de su texto desde «la solidaridad que hay entre los personajes» ${ }^{4}$.

\section{Una novelística filosófica}

Las novelas de Gambaro instauran universos imaginarios anclados en la realidad sociopolítica de la Argentina en las diferentes épocas de creación de los textos. Por ejemplo, Ganarse la muerte (1976) textualiza la represión institucionalizada, Dios no nos quiere contentos (1979), la vulnerabilidad de los más pobres durante la dictadura cívico-militar, Después del día de fiesta (1994), la miseria y la marginalidad de una Argentina capitalizada salvajemente. En estas tres novelas, así como en Promesas y desvaríos (2004), se comprueba una constante en el nivel de las elecciones temáticas, dado el tema recurrente de la relación victimario-víctima y de la pasividad de esta última, que las convierte en un corpus homogéneo, si bien las estrategias y modos de ficcionalización adoptados para la configuración de los mundos verbales imaginarios varían notablemente de uno a otro texto.

Ganarse la muerte es concebida por la autora como una metáfora del poder político del momento de producción ${ }^{5} \mathrm{y}$, en efecto, esta novela remite a hechos concretos de la realidad del país en ese momento, tales como: la falta de libertad, la censura, la tortura, la llamada «obediencia debida», la presencia militar en el gobierno, el secuestro de personas, la represión institucional, el miedo de la sociedad y su falta de reacción ante el terrorismo de Estado, la falta de tumba para los «desaparecidos»; en síntesis, la violencia de la Argentina de la década de 1970.

Desde el primer capítulo de esta novela se instaura el clima ominoso que recorrerá todo el texto y que también es una marca de estilo de tantas piezas dramáticas de Gambaro6 ${ }^{6}$, pues las apariencias amables esconden una realidad abyecta. Otras estrategias de ficcionalización empleadas por la autora para textualizar la violencia son la ironía, el sarcasmo, el humor ácido, que a través de la hiperbolización de las situaciones presentadas produce un efecto grotesco y absurdo ${ }^{7}$, así como un realismo exacerbado en la mostración de los extremos más sórdidos y crueles a los que puede llegar el ser humano, con el correlato de la total degradación del otro. Otro recurso estilístico puesto en juego por el texto es la intercalación de trozos líricos que quiebran el devenir narrativo. Este recurso es eficaz para mostrar planos axiológicos positivos o aspectos emocionales, que están voluntariamente excluidos de la textualización en prosa.

Como mencionaba supra, uno de los tópicos clave de Ganarse la muerte es el de la libertad para decidir sobre la propia vida. Para analizarlo, he recurrido a algunos constructos teóricos de

3 Entrevista telefónica a Griselda Gambaro (8 de marzo de 2000), realizada por Julio Rutman y transmitida en Radio Nihuil, Mendoza, Argentina, el 14 de marzo de 2000 (programa «Buena Letra»).

4 Declaración de Griselda Gambaro en la entrevista que le realizamos en Don Bosco, Buenos Aires, el 18 de octubre de 1999.

5 Ibidem.

6 Por ejemplo, Las paredes de 1963 y El campo de 1967, entre muchas otras.

$7 \quad \mathrm{El}$ «absurdo» es también la característica clave de la primera etapa de la producción teatral gambariana. 
Viktor Frankl ${ }^{8}$, para quien nuestra libertad esencial es la de elegir nuestra actitud incluso ante las peores adversidades. Esta libertad nos da forma como personas: el ser humano se determina a sí mismo, decide cuál será su existencia, única e irrepetible, y busca su sentido.

Veamos, entonces, algunos de los conceptos elaborados por Frankl en el análisis de esta novela de Gambaro, en la cual se describe, en veintitrés capítulos, el itinerario vital de una huérfana, Cledy, desde su reclusión y violación en un orfelinato, hasta su muerte a manos del torturador que ha usurpado el rol de su marido; pasando por su casamiento y su maternidad, período de felicidad transitoria alterada y definitivamente aniquilada por las continuas humillaciones y abusos a los que es sometida por su familia política y por el secuestro de su hija Alicia. Luego se sucede una nueva etapa feliz con su marido e hijos, la cual se acaba con la inexplicable muerte de los niños y con la convivencia forzada con el torturador que finalmente la asesina.

La novela se abre con la pregunta sobre el destino de cada nuevo ser que nace, «iSerá torturado o torturador?» (Gambaro, 1976: 9), lo cual implica una elección entre el rol de víctima y el de victimario, y con una primera explicitación del título de la novela: «[...] el misterio de la vida. Ya empieza ahí: en la elección, ganarse duramente la muerte, no dejar que nadie la coloque sobre nuestra cabeza como una vergüenza irreversible» (Gambaro, 1976: 9).

Esta relación vida/muerte es inherente a la existencia histórica, concreta, peculiar y singular de cada ser humano, la cual consiste en las acciones, las vivencias y también los sufrimientos que la persona va acumulando, y termina con su muerte, factor constitutivo del sentido mismo de la vida:

El sentido de la existencia humana se basa precisamente en su carácter irreversible. Por eso, sólo podremos comprender la responsabilidad de vida de un ser humano siempre que la entendamos como una responsabilidad con vistas al carácter temporal de la vida, que sólo se vive una vez (Frankl, 1997: 117).

Vida y muerte, entonces, están inseparablemente unidas, pues la vida no puede concebirse sin la muerte. En la novela esta idea está explicitada en dos poesías, la primera intercalada en el devenir narrativo y la segunda como cierre del texto:

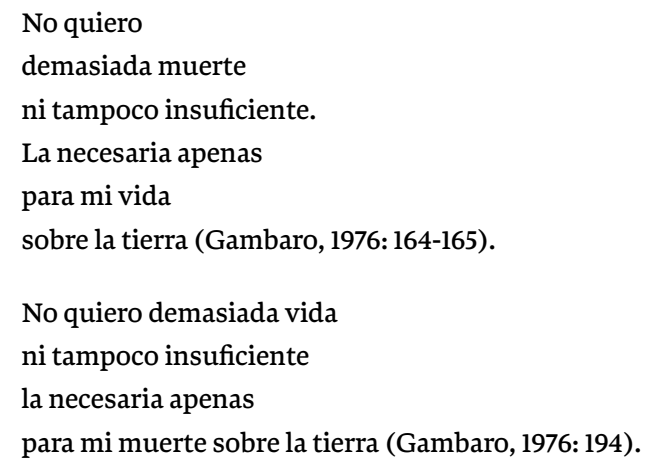

8 Filósofo austríaco nacido en 1905, fundador de la tercera escuela psicoanalítica vienesa (después de Freud y Adler), sobreviviente de los campos de concentración nazis. 
Por ende, «ganarse la muerte» significa ganarse la propia vida, no dejar que los demás sean sus artífices. Es por ello que la actitud de Cledy, de absoluta sumisión, incapaz de rebelarse contra sus torturadores, está puesta en tela de juicio en la novela. Por ejemplo, la ambigüedad situacional perversa a la cual está sometida Cledy no se justifica por su debilidad. En efecto, todo ser humano tiene, en última instancia, la posibilidad de decir no a lo abyecto y aberrante.

De acuerdo con el pensamiento de Frankl, el ser humano, dado el carácter histórico de su vida, es responsable en ella y ante ella; por ende, no puede ser un mero «paciente» de sus vivencias, sino convertirse en un «agente» consciente y responsable de su misión en la vida:

El hombre elabora la materia que el destino le brinda: unas veces creando y otras viviendo o padeciendo, se esfuerza por «desbastar» [quitar lo basto, lo grosero, pulir] su vida lo más posible para convertirla en valores, en valores de creación, de vivencia o de actitud (Frankl, 1997: 119).

Así, incluso ante la fatalidad más trágica, el ser humano es libre de comportarse de uno u otro modo ante su destino, de elegir una actitud y no otra ante el sino inevitable, para «elegir» su muerte al haber elegido su vida. Lo que se cuestiona desde el punto de vista ideológico en Ganarse la muerte es, entonces, la actitud de pasividad, tal como se ironiza en la primera página del texto: «Una eternidad de sujeción para que mueras dócilmente, hijito mío» (Gambaro, 1976: 9).

En Ganarse la muerte se instaura un universo verbal de desesperación salvaje, donde no hay amparo posible: en esta novela el desamparo es absoluto. Habrá que esperar a las novelas posteriores, como Dios no nos quiere contentos y, sobre todo, Después del día de fiesta, para que a lo más vil del ser humano se contraponga una axiología positiva encarnada en personajes compasivos y solidarios.

Dios no nos quiere contentos (1979), novela que Gambaro escribe durante su exilio barcelonés, no solo presenta un universo ficcional y las vivencias de los personajes que en él viven (Tristán, el niño mudo que quiere aprender a cantar; María, la niña que será prostituida; La Ecuyere, contorsionista y trapecista de circos que desaparecen y que ella debe buscar y encontrar una y otra vez; el bebé que perdió a su madre en un ómnibus atestado y que se unirá a Tristán y a la Ecuyere en su búsqueda perenne), sino que, fundamentalmente, plantea e intenta dar respuesta a algunos de los interrogantes existenciales más cruciales del ser humano. Es por ello que Dios no nos quiere contentos puede calificarse de «novela filosófica»: su narrador realiza, a lo largo de todo el texto, una serie de reflexiones sobre la naturaleza y la existencia humanas, desde la pregunta por la función del lenguaje y del silencio en la comunicación humana hasta la especulación sobre la muerte. Así, la novela discurre sobre la función del lenguaje en su posibilidad de subversión y de descubrimiento de la realidad; sobre el significado del silencio en tanto espacio abierto para una nueva comunicación y el peso semántico de la interacción gestual; sobre la importancia del cuerpo, en tanto realidad y en tanto signo; sobre la relación con el otro como (des)encuentro; sobre el egoísmo, la mezquindad o la grandeza de lo cotidiano; sobre la importancia de las ilusiones; sobre la infelicidad y el dolor inherentes a la existencia; sobre el peso insoportable de la verdad para los seres frágiles; sobre el arte; sobre el libre albedrío del ser humano; sobre la miseria y el trabajo; sobre el olvido y la memoria; sobre la muerte... 
El personaje de la Ecuyere muestra con su historia la posibilidad de ser libre gracias a un crecimiento espiritual que se desarrolla sobre la base de experiencias dolorosas. En efecto, la novela relata su vida como artista de circo, contorsionista y trapecista, y muestra cómo ella evoluciona desde la vanidad y el egoísmo hasta la solidaridad. Este crecimiento espiritual del personaje se produce a fuerza de los diferentes sucesos dolorosos a los que debe enfrentarse. El primero, la falta de reconocimiento hacia su trabajo, pues el circo siempre se traslada sin avisarle, lo cual la obliga a su búsqueda constante. Este deambular en busca del único espacio donde puede realizar sus valores de creación ${ }^{9}$ metaforiza la búsqueda de sentido existencial. Pero tal sentido no lo encontrará la Ecuyere en su actividad creativa, sino en la comprensión del prójimo en tanto ser necesitado de amparo. Así, el suceso que marcará el cambio evolutivo del personaje es la desaparición del objeto de su amor, el personaje del rotoso. A partir de este hecho, la Ecuyere comenzará a considerar al circo desde una mirada menos egoísta y esto hará que finalmente pueda darse cuenta de los abusos y crueldades que acontecen allí, por ejemplo, el asesinato de la «amiga mansa», una pobre mujer victimizada por el Patrón, y de uno de los viejos trapecistas. Este darse cuenta le permitirá decir no al último circo, es decir, negarse a permanecer en un espacio donde se abusa del prójimo. Es el dolor, entonces, lo que hace evolucionar espiritualmente al personaje, en el momento en que comprende que su pena, su padecer, también forma parte esencial de la existencia humana, y que a partir de ese dolor puede acercarse al otro en un intento de otorgarle su comprensión y su ayuda.

A través de los personajes sufrientes de la novela, Gambaro textualiza la experiencia universal del dolor, pero especialmente aquel padecer ocasionado por formas de poder y de relación abusivas, ese inmenso potencial de mal y de violencia que determinadas formas de cultura y sociedad han alimentado y que invaden los vínculos personales y sociales. Así, el circo dirigido por un Patrón cruel, autoritario y abusador, capaz de llegar hasta el asesinato de sus empleados, puede leerse como la metáfora de la realidad política de la Argentina durante la dictadura iniciada en 1976. Esta contextualización histórica se evidencia en la desaparición del rotoso, el hombre del cual se había enamorado la Ecuyere, que provoca la afirmación, por parte de uno de los vecinos, de que «iEn este país, todo se lo lleva el viento!»; en el asesinato de la «amiga mansa» del circo ante el cual el Patrón repite «Aquí no pasó nada»; y en las imágenes de tortura que suscita la propuesta de llevar a una comisaría al bebé perdido en un ómnibus: «La comisaría, pensó el bebé, a través de los efluvios que le pasaba Tristán, e imágenes de espanto lo asaltaron» (Gambaro, 1978: 251).

Esta lectura contextualizada nos permite afirmar que la crueldad y la pobreza textualizadas en la novela son la representación de un país atravesado por los crímenes de la dictadura, el terrorismo de estado, las villas-miseria, y que la fragilidad de los protagonistas tiene como referente a la vulnerabilidad de los marginados sociales bajo el gobierno de facto.

Por su parte, los modos de ficcionalización adoptados para la configuración del mundo verbal imaginario hacen de la novela una construcción compleja, pues las elecciones estilísticas

9 Para Frankl, en la vida se ponen en práctica tres tipos de valores: 1) Los valores experienciales que son las vivencias que tenemos y a las cuales les asignamos un valor; 2) Los valores creativos que consisten en cómo llevar a cabo un acto, es decir, es el poner en práctica nuestros proyectos; 3 ) Los valores actitudinales, que incluyen virtudes como la compasión, la valentía y un buen sentido del humor. 
van desde el tono reflexivo-lírico usado para las reflexiones sobre la existencia, pasando por lo real-maravilloso, en el caso de la textualización de los sueños del personaje de Tristán, hasta la utilización de los recursos de la ironía, la hipérbole y la comicidad de lo absurdo cuando se quiere lograr el tono humorístico con el cual se presentan algunas situaciones dolorosas.

Podríamos resumir los planteos de la novela diciendo que Dios no nos quiere contentos se constituye en un interrogante filosófico acerca del desamparo esencial del ser humano y en un interrogante histórico acerca de ese «empecinamiento de degradación y de crueldad» (Gambaro, 1978: 251) al que puede sucumbir la humanidad, donde las libertades civiles están anuladas y no parece haber lugar para la libertad espiritual, excepto después de un largo y doloroso recorrido vital como el del personaje de la Ecuyere. En efecto, el mundo representado en la novela es un panorama desolador en el cual, sin embargo, también sobreviven en momentos epifánicos los valores del amor, la solidaridad, la generosidad y la compasión. Nos explica Frankl, desde su experiencia en el campo de concentración nazi:

Fue entonces cuando aprehendí el significado del mayor de los secretos que la poesía, el pensamiento y el credo humanos intentan comunicar: la salvación del hombre está en el amor y a través del amor. Comprendí cómo el hombre, desposeído de todo en este mundo, todavía puede conocer la felicidad -aunque sea sólo momentáneamente- si contempla al ser querido. Cuando el hombre se encuentra en una situación de total desolación, sin poder expresarse por medio de una acción positiva, cuando su único objetivo es limitarse a soportar los sufrimientos correctamente -con dignidad- ese hombre puede, en fin, realizarse en la amorosa contemplación de la imagen del ser querido. Por primera vez en mi vida podía comprender el significado de las palabras: «Los ángeles se pierden en la contemplación perpetua de la gloria infinita» (Frankl, 1991: 46).

Luego, en su novela Después del día de fiesta (1994) volvemos a encontrar a un personaje de nombre Tristán. No es casual, pues según declaraciones de Gambaro, ambas novelas forman parte de una trilogía cuya segunda parte permaneció inédita hasta 2004: «El personaje [Tristán] forma parte de una trilogía. La novela del medio no la publiqué... quizás el año que viene. En la que tengo que publicar, Promesas y desvaríos, Tristán se muere, y me gustó mucho resucitarlo en Después del día de fiesta» ${ }^{10}$. Pero aún sin conocer esta intención autorial, al leer las tres novelas notamos inmediatamente que los tres personajes de nombre Tristán comparten la misma sensibilidad y son seres compasivos, cuya piedad hacia el prójimo es más intensa que cualquier otro rasgo de su carácter. En efecto, la axiología positiva donde la solidaridad es el valor superior, que se expresa en gestos generosos, gracias a la ausencia de egoísmo y la capacidad de entregarse al otro, y en actitudes de justicia, pues se le ofrece al prójimo lo que este merece en tanto ser humano digno de respeto y ayuda, está encarnada fundamentalmente en el personaje protagónico de Tristán.

También Después del día de fiesta puede considerarse una lectura de algunos aspectos de la realidad argentina de la década de 1990, como la violencia social y la niñez desamparada, desvalida, desnuda y hambrienta.

10 Declaración de Griselda Gambaro en la entrevista que le realizamos en Don Bosco, Buenos Aires, el 18 de octubre de 1999. 
En este «diagnóstico» de la Argentina del momento de producción del texto, además de la crueldad intrínseca a una sociedad violenta, se textualizan otros males sociales, tales como el trabajo alienante que en vez de liberar, esclaviza; un presente construido sobre una historia de pobreza, falta de educación y ausencia de solidaridad; la discriminación, tanto de los argentinos contra los inmigrantes (discriminación racial), como tanto de los argentinos entre sí (discriminación de clase); la pobreza; el desempleo; la prostitución; el femicidio.

\section{Un teatro de heroínas}

En cuanto a la producción dramática de Gambaro, extensamente estudiada, me enfocaré aquí en algunas de sus obras de la década de 1980 en las cuales la libertad (entendida como un «poder hacer») aparece como isotopía clave: La malasangre (1981) y Real envido (1984), cuyas protagonistas, Dolores y Margarita, se permiten la libertad de amar en contra de los designios de sus padres; Del sol naciente (1984), donde una geisha, a pesar de su estado de sujeción, no se somete nunca espiritualmente, y Antígona furiosa (1986), que nos enfrenta, al igual que su hipotexto griego, con la problemática de la obediencia a las leyes consideradas injustas y la libertad de no acatarlas.

En todas estas obras, quienes luchan por la libertad son personajes femeninos, pues un tema que ha ocupado a Griselda Gambaro a lo largo de toda su producción es la sumisión de la mujer en diversos contextos sociales. Por ello, Dolores de La malasangre y Suki de Del sol naciente se contraponen al mandato patriarcal de sumisión femenina: Dolores y Suki se instauran como verdaderas heroínas que se rebelan contra el autoritarismo y encarnan la lucha contra los abusos de poder, así como una axiología positiva en la que se destacan los valores de la solidaridad, la compasión y la lucha por la libertad.

Así, si bien gran parte de los personajes femeninos de Gambaro conforman un amplio universo de mujeres sometidas a la autoridad despótica de un hombre ${ }^{\mathrm{ll}}$, muchas otras toman conciencia y se transforman en agentes de la rebelión contra la arbitrariedad del poder. Surgen entonces las «heroínas» del teatro de Gambaro, como las mencionadas Dolores y Suki, a las que se suman, entre otras, Margarita de Real envido y Antígona de Antígona furiosa, que además reflejan la participación de la mujer en el ámbito público real. Por ejemplo, para la autora hay una relación directa entre la desobediencia civil de su Antígona y la posición de las Madres de Plaza de Mayo:

Pero yo sabía que iba a superar la idea de Sófocles, en el sentido de que yo iba a hablar con la voz de una mujer latinoamericana y con las voces de tantas mujeres que en mi país han hecho lo mismo que Antígona, que desobedeció la orden del rey Creonte y arrojó un puñado de tierra sobre el cadáver de su hermano, suficiente como para cumplir con la tradición de dar sepultura a sus muertos. Antígona es cada una de las Madres de la Plaza de Mayo que han pagado con su vida la desobediencia (Gambaro en Navarro Benítes, 2001: s/p).

11 Estos personajes sufren diversos tipos de maltratos físicos y psicológicos, comenzando, cronológicamente, por Emma, de El campo (1967), primer personaje femenino de la dramaturgia de Gambaro que aparece con signos de violencia física, y continuando con Graciela de Si tengo suerte (1970), Molly y Valentina de Dar la vuelta (1972/3) y la Mujer de El despojamiento (1974), entre otros. 
La Antígona gambariana, como la de Sófocles, se enfrenta a una ley que considera injusta y no claudica en sus ideales, aunque deba pagar con su muerte esta decisión ética. El acto de dar sepultura a Polinices reafirma el valor que poseen las leyes no escritas, esas que responden a imperativos morales, por sobre las normas humanas. El personaje de Antígona resuelve este dilema ético entre lo divino y lo humano: privilegia lo sagrado y pone límites a lo político, pero al hacer esto surge el agón y la tragedia. Así Antígona se erige en el símbolo de la dignidad humana en toda su tragicidad, al mismo tiempo que representa una idealización de lo femenino.

En Antígona furiosa también se textualiza la libertad más paradojal del ser humano: la de quitarse la vida. Antígona es la heroína de mayor intensidad dramática en toda la obra de Gambaro por llevar a cabo este acto abismal. Sobre todo, porque no se suicida presa de la desesperación ni en un estado melancólico, sino que lo hace reflexivamente, consciente de sus consecuencias y buscando justamente los efectos que su muerte tendrá sobre el poder de Creonte. A diferencia de otros personajes feneminos, como Cledy, Antígona sí tiene voz propia y potente: da testimonio de su padecer y sus alegatos son, además de conmovedores, un «J'Accuse...!» que sigue resonando después de su muerte.

En cuanto a Del sol naciente, en esta obra también hay una idealización de lo femenino en el personaje de una prostituta que posee la dignidad de una heroína. Si bien Suki, al ser una geisha, representa la sujeción por antonomasia, no se somete espiritualmente. El guerrero Obán, el epítome del poder masculino, intenta someterla sin lograrlo: Suki, a pesar de las amenazas de su señor, ejerce su libre albedrío mientras va dándose cuenta de la aterradora realidad del mundo exterior y comienza a cuestionar el egoísmo y el comportamiendo violento de Obán. La relación entre Suki y Obán se deteriora paralelamente a la toma de conciencia de Suki de la miseria que existe afuera.

Suki asume el rol de madre de los desaparecidos y olvidados y representa a la mujer como agente del cambio social. A sus acciones contestatarias se suma el simbolismo que entraña su acción final de despojarse de sus atavíos de geisha: se trata de un acto de libertad contra el rol tradicional de pasividad (sexual y política) que su sociedad le ha asignado.

En cuanto al dominio de lo familiar, las heroínas de la textualidad gambariana son hijas que ejercen su libertad a pesar del ámbito opresivo en el que viven: se niegan a aceptar los mandatos de un padre despótico que acciona los mecanismos del poder omitiendo cualquier tipo de consenso, aunque sus decisiones afecten a toda la familia. A esta situación se oponen las hijas insumisas de la dramaturgia de Gambaro, como Dolores, que declara a su madre que «iNadie me pondrá la mano encima, te dije! iNo me parezco a vos!»12 (La malasangre, Gambaro, 1984: 77), y como Margarita, que rechaza el casamiento que le ha arreglado su padre, el rey, haciendo énfasis en su derecho a tomar decisiones sobre su propia vida:

Margarita: [...] Soy tu hija.

Rey: iPor eso mismo! (Se sienta en el sillón). Quiero que te cases.

Margarita (lo enfrenta): ¿Yo? ¿Hablás de mí? ¿Dijiste «quiero»?

12 En el caso de las piezas teatrales de Gambaro, cito por la edición consignada infra en las Fuentes y consigno en el cuerpo del trabajo solamente el título de la pieza y el número de página. 
Rey (tan obsesionado tironeando y enrollando el chal que no la ve): ¿Eso dije? iSí, dije «quiero» porque soy rey! Cuando un rey dice quiero, itodos violín en bolsa! Boca cosida.

Margarita (canta):

Yo sólo quiero una mandarina

que van a traerme de la China

Casamiento yo no quiero

porque es cosa de mi vida (Real envido, Gambaro, 1984: 13).

Por su parte, La malasangre (1981) presenta una marcada referencialidad histórico-política en relación a un contexto de falta de libertades civiles: en esta pieza se textualiza una vez más la opresión familiar, encarnada en un padre autoritario al cual están sometidas madre e hija, y además la represión institucional que ese personaje, en tanto gobernante déspota, representa. El terror político, indexado por las cabezas cortadas que se pregonan como melones maduros, recorre toda la obra. La esfera de lo privado se une a la esfera pública a través del autoritarismo que las impregna, y así, tanto la institución familia como la institución gobierno están atravesadas por la represión ejercida por el padre despótico y el gobernante tirano, roles que, precisamente, cumple un único personaje.

En La malasangre, la alusión a las prácticas represivas de la Argentina contemporánea es oblicua, y se explica, desde la instancia de producción del texto, por razones de verosimilitud y de censura. Esta referencialidad histórico-política un tanto elíptica, pues la ambientación remite a la época de Juan Manuel de Rosas (siglo XIX), no presentó, según Gambaro, un impedimento para su correcta interpretación por parte de sus primeros espectadores, quienes lograron ver la vinculación del texto con la realidad política contemporánea:

Se estrenó en las postrimerías de la dictadura militar y la gente venía de un largo silencio; entendió que esa historia de amor de La malasangre era un pretexto para decir otras cosas. Decir que los argentinos seguíamos vivos, de que se podía y se debía gritar, de que de una manera o de otra no era posible seguir soportando el mutismo impuesto por la represión (Gambaro en Giella, 1985: 36).

Estos personajes representan una nueva generación de mujeres, que han aprendido que la sumisión no es natural, sino cultural, y que la violencia no es aceptable, sino que debe ser denunciada. Por otro lado, tanto en Real envido como en La malasangre las relaciones hombre-mujer son trasladadas al plano político: el amor de Dolores por Rafael, su preceptor jorobado, y el de Margarita por Valentín, lacayo del príncipe con quien debería casarse, se ubican al margen del orden establecido por la máxima autoridad, el padre-gobernante. Ambas parejas de amantes no solo optan por reconocer un sentimiento que sus convenciones sociales les prohíben, sino que lo encuadran en el marco de una rebelión mayor: «no sólo te elijo a vos, elijo cabezas sobre los hombros...» (La malasangre, p.104), declara Rafael; mientras que Margarita y Valentín se quedan en la corte fingiendo sumisión, pero decididos a actuar. Nos encontramos, así, en la intersección de los dos ámbitos, el privado y el político, pues la familia, como ha dicho Gambaro, puede ser también «una pequeña dictadura en la que los roles a veces están marcados a fuego» (Gambaro en Halperín, 1985: 24). 
Vemos así que en estas obras de Gambaro los personajes femeninos pasan de la pasividad a la acción efectiva, a partir de una diferencia de perspectiva que la dramaturga señala como propia de la condición femenina:

La mujer imprime algo diferente en la cultura. Y lo que la mujer imprime en la cultura es la diferencia de su género, diferencia de ver la vida y la muerte, de querer nacer a otra libertad, a otra igualdad, a otra distribución del poder (Gambaro, 1998: 38).

\section{Conclusiones}

Griselda Gambaro, autora reconocida nacional e internacionalmente sobre todo por su producción dramática, aunque menos estudiada como narradora por la crítica especializada, posee una obra narrativa de calidad incuestionable. Su novelística, sin dejar de estar anclada en el contexto sociopolítico argentino y textualizando, por ende, los planos de la realidad de ese contexto, se aleja de los códigos establecidos por el realismo canónico, predominante entre los miembros de su generación, e instaura una visión del desamparo esencial del ser humano, un desamparo que va más allá de las circunstancias histórico-políticas de un momento o de un país determinados. La de Gambaro es una mirada filosófica que ahonda en la incomunicación y en la soledad humanas a través de un imaginario de seres desamparados que, a pesar de la crueldad que los rodea y violenta, logran establecer vínculos solidarios donde la convivencia afectuosa se hace posible y buscan su libertad espiritual incluso estando atravesados por dispositivos de enajenación totalitarios.

Por su parte, las obras teatrales de Gambaro están vertebradas por la representación constante de los mecanismos de funcionamiento del poder, ya sea en su dimensión político-social, ya sea como vínculo omnipresente en las relaciones interpersonales. A partir de esta problemática, Gambaro indaga en profundidad acerca de las posibilidades y limitaciones en la instauración y construcción de un sujeto libre. En efecto, el objeto al que el sujeto apunta es siempre el mismo: la libertad. La dramaturgia de Gambaro consigue, a través de estos rasgos esenciales, una unidad poética inconfundible dentro del sistema teatral argentino.

Para los personajes de Gambaro que he examinado aquí, el ser humano puede conservar su libertad espiritual, su independencia mental, incluso en un contexto de tortura psíquica y física. El planteo último de los textos es que al ser humano se le puede arrebatar todo salvo una cosa: la libertad de elegir la actitud personal ante un conjunto de circunstancias dadas, una libertad íntima que nunca se pierde y que configura nuestra condición humana: «¿Qué es, en realidad, el hombre? Es el ser que siempre decide lo que es. Es el ser que ha inventado las cámaras de gas, pero asimismo es el ser que ha entrado en ellas con paso firme musitando una oración (Frankl, 1991: 94)». 


\title{
Bibliografía
}

\section{Fuentes:}

У GAMBARO, Griselda (1976). Ganarse la muerte. Buenos Aires: Ediciones de la Flor.

$\checkmark$ GAMBARO, Griselda (1979). Dios no nos quiere contentos. Barcelona: Lumen.

У GAMBARo, Griselda (1984). Teatro 1: Real envido. La malasangre. Del sol naciente. Buenos Aires: Ediciones de la Flor.

У Gambaro, Griselda (1989). Teatro 3: Viaje de invierno. Nosferatu. Cuatro ejercicios para actrices. Acuerdo para cambiar de casa. Sólo un aspecto. La gracia. El miedo. El nombre. El viaje a Bahía Blanca. El despojamiento. Decir sí. Antígona furiosa. Buenos Aires: Ediciones de la Flor.

\ GAMBARo, Griselda (1999). Escritos inocentes. Buenos Aires: Norma.

\section{Bibliografía citada:}

У FRANKL, Viktor E. (1991). El hombre en busca de sentido. Barcelona: Herder.

У FRANKL, Viktor E. (1997). Psicoanálisis y existencialismo. De la psicoterapia a la logoterapia. México: Fondo de Cultura Económica.

У GAMBARO, Griselda (1998). «Nuevas pasajeras». Teatro CELCIT. Revista de teatrología, técnicas y reflexión sobre la práctica teatral iberoamericana, 8.9-10, pp.36-38.

\ GIELlA, Miguel Ángel (1985). «Entrevista: Griselda Gambaro». Hispamérica, 14.40, pp. 35-42.

$\checkmark$ HALPERÍN, Jorge (1985). «Conversación con la escritora Griselda Gambaro. El artista y sus extraños presagios». Diario Clarín, 16-6-1985, p. 24, col. 1.

ע MORELl, Hortensia R. (1991). «La narrativa de Griselda Gambaro: Dios no nos quiere contentos». Revista Iberoamericana, 57.155-156, pp. 481-494. https://doi.org/10.5195/REVIBEROAMER.1991.4908

У NAVARRo BeNíteS, Joaquín (2001). «La transparencia del tiempo, entrevista a Griselda Gambaro». Cyber Humanitatis (Revista de la Facultad de Filosofía y Humanidades, Universidad de Chile), 20 (Primavera 2001). https://web.uchile.cl/publicaciones/cyber/20/entrevl.html [22-07-2019].

\author{
Susana Tarantuviez \\ Instituto de Literaturas Modernas \\ de la Facultad de Filosofía y Letras \\ de la Universidad Nacional de Cuyo \\ CIUDAD DE MENDOZA (M5502JMA) \\ Argentina
}

